\title{
Technology Integration in Higher Education: The use of Website Design Pedagogy to Promote Quality Teaching and Learning
}

\author{
Joyce West and Makwalete Johanna Malatji \\ University of Pretoria, Faculty of Education, Department of Early Childhood Education, South \\ Africa \\ joyce.west@up.ac.za \\ makwalete.malatji@up.ac.za
}

\begin{abstract}
The integration of technology within higher education, specifically teacher education, has become vital in preparing pre-service teacher for the 21st-century classroom. Literature shows that the integration of technology allows students to engage deeply with content and promote authentic learning. Over two years, pre-service teachers who enrolled for a language education module at a university in South Africa were tasked with designing their own websites using Google Sites - an online, free, collaborative, web-based application that forms part of Google's G Suite. As part of the website design assignment, they had to include a blog, informative text and a YouTube video explaining a language-teaching-related topic. The study was conducted from an interpretivist paradigm and an embedded mixed-methods research design. The technological pedagogical content knowledge model served as the theoretical framework. Data collected from 214 preservice teachers revealed that the use of website design pedagogy promoted the integration of different types of knowledge domains, authentic learning and proximal development. The pre-service teachers furthermore reported that the use of website design pedagogy better prepared them for the 21st-century classroom. Challenges that the students experienced included inadequate access to the internet and problems with recording and uploading videos. This study advocates for authentic learning and scaffolding and therefore recommends that higher education institutions integrate technology holistically by adhering to the principles of the technological pedagogical content knowledge model.
\end{abstract}

Keywords: authentic learning; Google Sites; higher education; pre-service teachers; teaching and learning; technological pedagogical content knowledge (TPACK) model; technology integration; zone of proximal development (ZPD)

\section{Introduction}

The 21st century is known for rapid technological advances and is associated with the implication of the socalled fourth industrial revolution. The fourth industrial revolution has and is "revolutionising how we conceptualise and act towards teaching and learning" (Skhephe, Caga and Boadzo, 2020, p.43). Blinder (2006) anticipated the implications of the fourth industrial revolution and recommended upskilling the use of technology and equipping teachers to navigate all information and communications technology, which includes computers, assistive devices, applications and software. Pre-service teachers therefore need to be encouraged to acquire 21st-century knowledge and skills, such as technology literacy and the integration of technology within teaching and learning (Ejikeme and Okpala, 2017).

Various researchers (e.g., Calvo and Villarreal, 2018; Du Toit and Verhoef, 2018; Green, Jones and Burke, 2017) argue that pre-service teachers' technology literacy skills and the integration of technology during teaching and learning within higher education have been insufficiently addressed and researched. Thus, the rationale behind this study was to determine how the use of Google Sites, an online, web-based application of Google's G Suite, can be used within higher education to promote quality teaching and learning. The interactive online platform was selected for this study because of its user-friendly nature and because it allows pre-service teachers to work collaboratively on the design of a website. The main research question was formulated as follows: How can the use of website design as pedagogy promote quality teaching and learning in higher education? According to Nwana (2008), for the effective incorporation of technology in higher education, research should be done to determine the challenges that affect pre-service teachers' teaching and learning. The study therefore also investigated the pre-service teachers' experiences of and challenges in designing websites using Google Sites as platform.

\section{Technology literacy}

Technology literacy refers to the ability to use technological skills and tools during learning (Ejikeme and Okpala, 2017). The United States Department of Education (1996, p.7) defines technology literacy as "computer skills and the ability to use computers and other technology to improve learning, productivity and performance". Thammasaeng, Pupat and Phetchaboon (2016) define a technologically literate person as someone who has the 
ability to use computers, communication tools and social networks appropriately and can define, access, manage, evaluate, integrate, create and present information using technological applications. However, the term "technology literacy" is not limited to devices, such as computers, but rather "the application of scientific knowledge for practical purposes" (Ejikeme and Okpala, 2017, p.1164). Technology literacy is also associated with digital literacy, online learning and e-learning (Hassan and Mansor, 2009). There is a global shift towards online and e-learning, which can be observed through the improvement or replacement of traditional learning modes, such as classroom experiences, textbook study, CD-ROM and traditional computer-based training (Calvo and Villarreal, 2018; Skhephe, Caga and Boadzo, 2020). Traditional classroom experiences and direct instruction are continuously being replaced by online education. The integration of technology within teaching and learning, also known as "blended and hybrid learning", also emphasises the shift towards online learning also known as e-learning.

\section{Integration of technology into teaching and learning}

Depending on how technology was used, existing research describes the overwhelmingly positive results and benefits of technology integration into higher education (Du Toit and Verhoef, 2018; Waghid and Waghid, 2016). According to Okpala and Ejikeme (2017), pre-service teachers' potential is unlocked by the integration of technology within teaching and learning. The benefits of technology integration into education include enhancing and promoting quality teaching and learning (Waghid and Waghid, 2016), the stimulation of social interaction and critical thinking, the cultivation of excitement, and the enhancement of collaboration among students (Wankle, 2011). Technology integration has also been associated with students gaining ownership, being creative and becoming problem solvers in the fourth industrial revolution (Gardner, 2014; Skhephe, Caga and Boadzo, 2020; Wankle, 2011). Also, technology integration can contribute to developing skills that would allow learners to access the global economy and improve their lives by unlocking the ever-changing world and to becoming game changers in society (Kiilu and Muema, 2012; Skhephe, Caga and Boadzo, 2020). Moreover, the Horizon Report of the New Media Consortium (cited in Adams Becker et al., 2017) suggests that the integration of technology helps to improve the internationalisation of higher education.

Although various benefits have been reported, various challenges and concerns have also been raised with regard to the integration of technology during teaching and learning within higher education. Challenges have been raised regarding cost-effectiveness, access and equity (Wainer et al., 2008), which also address the achievement gap. The achievement gap refers to a discrepancy in the "academic performance between student groups, defined by socioeconomic status, race, ethnicity, or gender" (Adams Becker et al., 2017). Other challenges that have been reported include increased plagiarism, the loss of concentration (attention, mindfulness and focus), the uncertainty regarding the role of the lecturer and a lack of resources (necessary devices, applications and internet availability) (Adams Becker et al., 2017).

The training of lecturers with regard to the integration of technology in teacher education programmes and curricula is another matter of concern (Georgina and Olson, 2008; Kiilu and Muema, 2012; Skhephe, Caga and Boadzo, 2020). Concerns about the training of lecturers stem from unrealistic expectations and mistaken assumptions about learning enhancement through technology integration (Du Toit and Verhoef, 2018). A critical document review of articles on technology-integrated learning from 2005 to 2010 by Kirkwood and Price (2014, p.26) concludes that there are expectations that "introducing technology would, by itself, bring about changes in teaching/learning practices". Du Toit and Verhoef (2018), Flavin (2017) and Kirkwood and Price (2014) all argue that this is a mistaken assumption. Adams Becker et al. (2017) also raise concerns about technology literacy being viewed by some lecturers as an isolated technological skill.

In this study, careful consideration took place regarding both the benefits and the reported challenges concerning technology integration. Du Toit and Verhoef (2018) encourage higher education role players to discover a more holistic and embodied understanding of technology in higher education by critically engaging with questions about the use and integration of technology in higher education. A holistic view and embodied understanding of technology in higher education refer to the acknowledgment of pre-service teachers as embodied beings (Du Toit and Verhoef, 2018). Clark and Chalmers (1998) agree and explains that if pre-service teachers are viewed as embodied beings then one will not view technology as only tools to be integrated, but that the technological tools are implemented and integrated in a holistic way that aligns with who we are. To gain a more holistic view and embodied understanding of technology in higher education as part of teacher 
preparation, this study viewed technology integration through the lens of the technological pedagogical content knowledge (TPACK) model as a theoretical framework.

\section{Theoretical framework of the study: TPACK}

The TPACK model comprises of distinctive kinds of knowledge domains in which instructors have to become proficient to effectively integrate innovative technology in teaching and learning processes. (Koehler et al., 2014). Koehler et al. (2014) shows that the TPACK theory is used by researchers and teachers to describe the competences student and in-service teachers should develop in order to integrate technology within education and to understand and advance teachers' integration of technology in teaching and learning. The TPACK model is based on the notion of pedagogical content knowledge (PCK), which refers to the ability to combine content knowledge in a specific domain or school subject with pedagogical approaches to foster student learning (Saubern et al., 2019).

The TPACK framework has been used in various studies to describe teachers' knowledge (Chai, Koh and Tsai, 2010) and to understand the interplay of three unique domains of knowledge necessary for teaching, namely content, pedagogy and technology (Moe and Polin, 2016). In higher education, it is important to consider the different types of knowledge that pre-service teachers need to acquire for them to be prepared for the 21 stcentury classroom. The integration of technology into teacher education exposes pre-service teachers to new technological skills and assists them in becoming technologically literate. Therefore, a theoretical framework is needed to acknowledge the interaction that takes place between pre-service teachers' technological knowledge and content knowledge, as well as how they are going to apply their knowledge in their classrooms (i.e., pedagogical knowledge) (Koehler and Mishra, 2009). The TPACK model that was used in this study acknowledges a variety of knowledge and skills that a teacher needs. Moreover, the theory was found to be successful in teaching pre-service teachers how to integrate technology in their classrooms (Harvey and Caro, 2017).

Shulman (1987) pointed out that the TPACK framework builds on explanations of pedagogical content knowledge (PCK) to describe how teachers' understanding of educational technologies and of PCK interact with each other to produce teachers that can teach effectively with technology. Thus, pre-service teachers in this paper were equipped with TPACK in order to equip them with the necessary knowledge and skills to use technology within the literacy classroom. The TPACK model has been developed over time, with complete explanations found in the work of Koehler and Mishra (2009) and Mishra and Koehler (2006). The TPACK comprises of three fundamental components: technological Knowledge (TK), content knowledge (CK) and pedagogical knowledge (PK). Another important aspect of the TPACK model is the interactions among the different types of knowledge, for example technological content knowledge (TCK), technological pedagogical knowledge (TPK) and pedagogical content knowledge (PCK). The essence of the TPACK model is, therefore, the interaction of diverse types of knowledge required by a teacher for the effective integration of technology during teaching and learning. The TPACK model and the way the different types of knowledge are integrated are depicted in Figure 1.

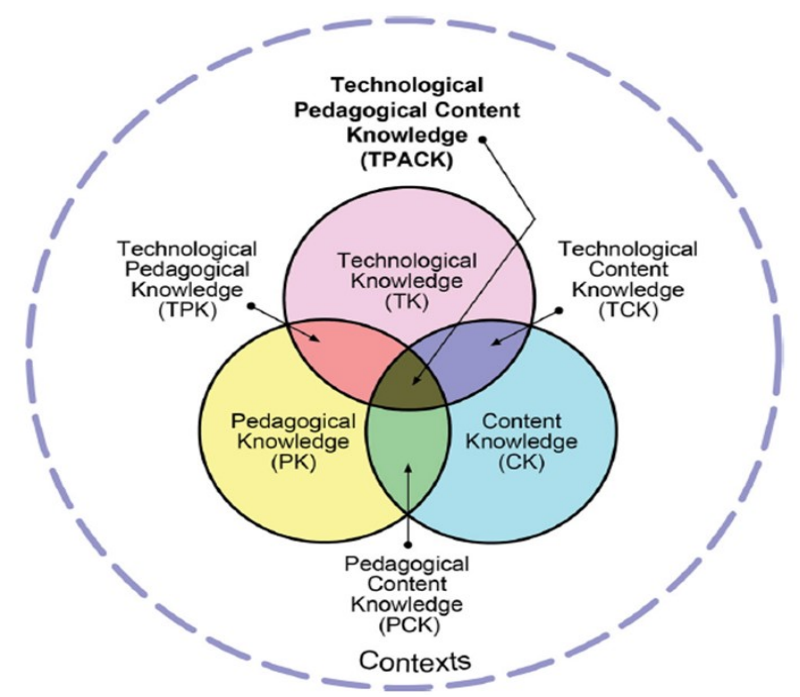

Figure 1: TPACK framework (Koehler and Mishra, 2009; Mishra and Koehler, 2006) 


\section{Integrating the TPACK model with Google Sites}

Developing technology literacy and confidence in integrating technology is a key factor in achieving TPACK integration (Tai, 2015). Flavin (2017) therefore explains that teacher education and training programmes should deliberately infuse the use of technology throughout the programme to make a significant impact on pre-service teachers' learning. Tai (2015) articulates that technology-rich teaching experiences assist teachers in developing their TPACK. Allen and Seaman (2010) point out that pre-service teachers at higher education institutions should take at least one online course or be exposed to technology integration during teaching and learning to help prepare them for the 21st-century classroom. For pre-service teachers to effectively integrate technology during teaching and learning, Lambert and Gong (2010) suggest that they receive training on how to connect different knowledge domains (i.e., TCK, TPK and PCK) and skills when teaching. Pre-service teachers in this study were therefore trained on how to design a website which involves TCK, TPK and PCK.

Pre-service teachers' CK was developed by providing them with instruction on language education in the Foundation Phase (children of 5 to 9 years of age). The language education module consisted of 10 learning units that addressed various topics related to language teaching, such as the science of reading, reading theories and multilingualism within the South African classroom. The pre-service teachers' PK was developed by providing them with exposure to practical and pedagogical aspects of teaching a language. PK in this study therefore refers to different teaching strategies, approaches, methods, techniques and resources. The CK and PK were presented in an integrated manner (i.e., PCK) for the pre-service teachers to understand how theory and practice inform each other. $g$ (2015) explains that PCK reflects the connections between subject matter and instructional strategies. Benavot (2015) and Lye (2013) emphasise that teaching and learning are endorsed when pedagogy is adapted to meet the content and skills of varying subject areas, such as languages.

Furthermore, the pre-service teachers' TK was developed by providing them with training on how to use Google Sites to create their own language education websites. Google Sites is an interactive and collaborative website design application that has been optimised for businesses, academic and social networking purposes. Online platforms, such as Google Sites, allow pre-service teachers to collaborate online and provide them with the opportunity to develop their technology literacy by engaging deeply with the content (Ejikeme and Okpala, 2017).

As part of the summative assessment of the module, the pre-service teachers had to create a website using Google Sites that contained information on language education and language development theories, as well as a blog and a YouTube video in which they discussed linguistic diversity and multilingual classroom dynamics. The integration of TK and CK (TCK), as well as TK and PK (TPK), is therefore also evident in this study. TCK in this study therefore refers to how the pre-service teachers used their TK to present their CK (cf. Benavot, 2015), and TPK refers to how technological tools can promote teaching and learning and how the teaching process itself may change an outcome by using specific tools (Boschman, McKenney and Voogt, 2015). Since the TPACK model does not privilege one knowledge area over the other, but rather advocates for the mediation of different knowledge domains (Moe and Polin, 2016), one can argue that TPACK contributes to authentic learning.

\section{Authentic learning in the study}

Authentic learning refers to a wide variety of educational and instructional techniques that are focused on connecting what students are taught in school to real-world issues, problems and applications (Dolapcioglu and Doğanay, 2020). Lombardi (2007) states that authentic learning requires learners to make connections to existing knowledge and deeply explore new knowledge in context. Creating authentic learning activities or experiences for pre-service teachers requires the integration of technology to achieve authentic teaching and learning (Archambault, Debruler and Freidhoff, 2014; Bjekic, Krneta and Milosevic, 2010; Latham and Carr, 2012). Pre-service teachers gain authentic learning through complex tasks that they have investigated over a sustained period, requiring a significant investment of time and intellectual resources (Johnson, 2012). Additionally, for authentic learning to occur, "learners must be engaged in an inventive and realistic task that provides opportunities for complex collaborative activities" (Herrington and Oliver, 2010: 1). Authentic learning therefore requires learning opportunities that pre-service teachers can benefit from and that will be worthwhile once they heave higher education (Herrington and Oliver, 2010). Johnson (2012) argues that there is no singular criterion for authentic learning; instead, it is a collection of characteristics. Furthermore, Herrington (2006), Herrington and Oliver (2010) as well as Johnson (2012) believes that authentic learning can be promoted through 
the use of technology integration. During this study, pre-service teachers created their own websites with the aim of experiencing authentic learning.

\subsection{Zone of proximal development in the study}

Shulman (1986) and Mishra and Koehler (2006), authors of the TPACK model, emphasise the importance of educational learning theories such as constructivism and the social learning theory as integral to the TPACK construct. One such theory is Vygotsky's (1978) theory of the zone of proximal development (ZPD). In short, the ZPD refers to the difference between what a learner can do without support and what he or she can achieve with guidance and encouragement from a skilled partner (Fani and Ghaemi, 2011). The ZPD furthermore highlights the development of knowledge and skills through scaffolding, modelling, coaching and authentic learning. The ZPD is therefore anchored in the notion that the development of knowledge and skills is supported by scaffolding from more knowledgeable people, peers or learning tools. Teacher education has also shown that "successful implementation of the TPACK is achieved through scaffolding its use in practice, through learning by designing" (Moe and Polin, 2016, p.78). Various researchers, for example Vygotsky (1978) and Iszatt-White, Kempster, and Carroll (2017), support the view that knowledge is co-constructed and that individuals learn from others during experiences. Johnson (2012) argues that pre-service teachers should help others connect new experiences to existing knowledge in order to understand how technology can support teaching and learning. Informed by the ZPD, the pre-service teachers had to work in groups to support one another and to perform tasks beyond their current level of capabilities.

\section{Research methodology and design}

This study investigated the use of website design pedagogy as a way to promote quality teaching and learning in higher education through an interpretivist lens by adopting an embedded mixed-method research design. The embedded mixed-method design provided two sets of data, where one set played a supportive, secondary role (Behmanesh et al., 2020). The embedded mixed-method design served as a means of unifying a primary qualitative dataset with a secondary quantitative dataset. The qualitative and quantitative data were collected simultaneously using an online questionnaire. Over two years (2019 and 2020), 586 second-year pre-service teachers who had been enrolled for a language education module as part of the curriculum of their Bachelor of Education (BEd) degree at a university in South Africa were asked to voluntarily complete an online questionnaire. A total of 214 pre-service teachers voluntarily participated. The questionnaire was informed by the TPACK model and consisted of 20 reflective questions. In the questionnaire, 13 questions were open-ended, and the remaining seven were closed-ended. For this paper, the data was only analysed qualitatively. Data analysis was conducted using Atlas.ti, a qualitative software program. The data were thematically analysed by identifying codes, categories and, lastly, themes.

\section{Findings and discussion}

The findings of this study are based on 214 voluntary, anonymous responses by second-year pre-service teachers to an online open-ended questionnaire. In 2019, 142 (57\% response rate) pre-service teachers responded to the questionnaire. In 2020, 72 (32\% response rate) pre-service teachers responded. Within the data, we identified four themes. Having conducted extensive data analysis with Atlas.ti, it was evident that the four themes were connected by describing how the use of Google Sites could promote quality teaching and learning in higher education.

The first theme explains how the design of websites using the Google Sites application as part of Google's $G$ Suite provides the pre-service teachers with the opportunity to integrate different types of knowledge (CK, PK and TK) as emphasised by the TPACK model. The second theme addresses the importance of integrating different types of knowledge to better prepare pre-service teachers for the 21st-century classroom. The third theme describes how the use of Google Sites promotes quality teaching and learning, owing to its adherence to the principles of authentic learning. The fourth theme focuses on how the use of Google Sites helps pre-service teachers to reach their ZPD as theorised by Vygotsky (1978). In the following sections, the four themes are discussed. Next to the quotations from the pre-service teachers' responses, the number of the document and the quotation from the Atlas.ti report are placed in brackets.

\subsection{The design of websites to integrate and develop different types of knowledge}

The first theme of this study addresses how the design of language education websites using Google Sites resulted in the integration and development of different types of knowledge. The findings indicate that the pre- 
service teachers developed technological, pedagogical and content knowledge during the assignment. The integration of different types of knowledge aligns with the TPACK model, since it acknowledges a variety of knowledge and skills that a teacher needs for teaching learners in the 21st century (Harvey and Caro, 2017). Moreover, Harvey and Caro (2017) state that the TPACK model has also been found successful in teaching preservice teachers how to integrate technology in classrooms.

\subsubsection{Technological knowledge}

After completing the assignment, the pre-service teachers were asked to reflect on their experience and the challenges they had encountered. From the data, it was evident that the pre-service teachers had gained TK but had also experienced various technological challenges. TK refers to the specific technology tools (computer, phones, games, the internet and Google applications) that can be used to promote teaching and learning and how the teaching process itself may change the outcome of using specific tools (Boschman, McKenney and Voogt, 2015).

When the pre-service teachers were asked whether the assignment had challenged their TK, $85.7 \%$ of them responded with a "yes". From 160 responses, it was evident that they had experienced various technological challenges that related to the design of websites, the use of the Google Sites application and the recording, editing and uploading of videos onto YouTube and Google Sites. Some of the pre-service teachers also reported having difficulties with the availability of devices and internet connectivity.

Many of the students explained that they had struggled with "creating the website" (e.g., 6:37, 8:11 and 8:23), "setting up the website" (8:10) and "the design of the website" (8:45). One pre-service teacher said that it was difficult "working with a program that I haven't worked with before" (8:8). Other pre-service teachers explained that they had "struggled the most with learning how everything works to create a website" (8:24), "learning to understand the tool" (6:48) and "mostly the technical things like typing and putting everything together" (12:34). Other pre-service teachers experienced problems with "making the website look presentable" (8:3), the "formatting of the website" (8:25) and "creating a website page that was aesthetically pleasing" (8:27). One preservice teacher explained that "finding the right backgrounds and themes to make the site perfect" (8:55) was a challenge, while another pre-service teacher wrote, "CHANGING THE FONT!! Everything I learnt quite easily, but the font got the better of me! (haha)" (8:36).

Some of the pre-service teachers struggled with the Google Sites application because "the site was very limiting. You could not choose multiple colours or fonts" (12:1) and because there was a "lack of design strategies and options in Google Sites" (12:27). One pre-service teacher explained, "[You] cannot customize your own page, changing one page changes the entire website" (12:161). Moreover, some pre-service teachers did not know "how to publish the site" (8:7) and one pre-service teacher said that they had struggled with "making our website public" (8:9). Other challenges related to the Google Sites application included "inserting links and adding sliding panes" (8:20), "linking the different pages together" (8:32), "adding tabs to my specific page so that I did not have all my information on 1 page" (8:44), "uploading the cover photo" (6:31) and "inserting pictures and videos" (8:21). One pre-service teacher elaborated that "I find that I struggled to personalize the page (12:14) and another said that "the video made it difficult because we had to embed it on the webpage" (12:55).

Other technological challenges related to the recording, editing and uploading of a video onto YouTube and Google Sites, as one pre-service teacher wrote, "when it came to video oh my word". The pre-service teachers explained that they had "struggled a long time to try and find the perfect app for the video" (6:7) and that it was challenging "to upload the YouTube video" (e.g., 8:4, 8:14, 8:16 and 8:30) and "editing a video" (8:13). One preservice teacher said that "editing my visuals for my YouTube video" (8:38) was the greatest challenge, whereas another pre-service teacher explained that "finding an appropriate app for video making and editing the video" (8:50) was the biggest challenge.

Although all pre-service teachers had free access to computers and the internet (e.g., Wi-Fi) in 2019, some of the pre-service teachers still experienced technological challenges with regard to internet connectivity. One preservice teacher explained that "the website assignment needed data and some of us don't live on campus where there's wifi" (18:44). In 2020, due to Covid-19-related circumstances, pre-service teachers did not have access to the computer laboratories or the campus internet of the university, which led to 10 out of the 241 pre-service teachers reporting experiencing challenges with internet connectivity and the availability of computers. One pre-service teacher said that "connecting to the internet" (8:39) or "connectivity issues" (8:41) made it difficult 
to design their websites. Another one said, "I did not enjoy working on Google Sites ... [because it] required [a] very strong internet connection" (12:149).

From these quotations, it is evident that some of the technological challenges the pre-service teachers experienced related to their own TK and literacy skills, whereas some of the challenges were due to the Google Site application itself or the availability of devices and internet connectivity. From the data, it was also evident that although the pre-service teachers had experienced various challenges, their TK had increased significantly as well. Within the data, 84 responses were linked with various TK that the pre-service teachers had gained from this assignment. For example, one pre-service teacher said, "I learned a lot, technology wise [sic]" (17:10) and another, "I learnt new things, like how to make a website" (17:14). Some of the pre-service teachers explained that they now knew how to "create a website" and "decorate the website" (17:50) and "where to get free pictures" (17:20). The majority of the pre-service teachers explained that they had "enjoyed making the website" (17:31) because they were now "able to use technology more effectively" (17:37). One student explained that "the thought of being technologically savvy" (17:137) had made the assignment enjoyable and worthwhile. Another student said that the assignment had encouraged him or her "to be computer literate" (18:23). Another pre-service teacher elaborated that they were able to use different types of media "to make the website happen and that has developed a lot of skills that we already have and taught us new ones... [which] helped us structure work that would otherwise be boring in a fun way" (18:8).

From the pre-service teachers' responses, it was evident that even though the design of a language education website using Google Sites was challenging, they had enjoyed it and gained more TK and skills. Although the preservice teachers had gained TK, it was evident from the data that they had also gained CK and PK.

\subsubsection{Content knowledge and pedagogical knowledge}

CK in this study refers to the content that the pre-service teachers were exposed to and had to engage with during the language education module. PK refers to the practical and pedagogical aspects of teaching a language. When the pre-service teachers were asked whether the assignment had increased their CK, $90 \%$ of them responded with a "yes". When they were asked whether the assignment had increased their PK, 89\% of them responded with "yes". After that, the pre-service teachers were asked to elaborate on the CK and PK they believed they had gained. From the pre-service teachers' responses, it was evident that they had learnt about the "theories on how to teach language" (23:1) and that "learners' mother tongue must be taken into consideration in the classroom and it is important that teachers keep enough resources in the classroom for learners to strengthen their mother tongue" (23:2). One pre-service teacher also said, "It provided me with a more holistic view on teaching a language" (23:5). Others said they had learnt about "creating an inclusive classroom" (23:6) and that they now had "a clear awareness of language difficulties that teachers face in the South African classroom context" (23:10). One pre-service teacher said that the assignment had taught her about how "cultural diversity plays an important role in teaching language and how different methods can work together to teach languages in an effective manner" (23:26). Pre-service teachers also said that they were "more knowledgeable about the different reading methods and how to use them in the teaching environment" (23:14) and that the assignment had equipped them with "the steps you need to take to teach language successfully" (23:17). "I now know what aspects to focus on when teaching language" (23:29), another pre-service teacher added.

Since the assignment required the pre-service teachers to research language teaching, to write a blog and to record a video for their website, the pre-service teachers benefited greatly from the assignment. The pre-service teachers explained that they were "able to do a lot of research on the teaching of languages in the Foundation Phase ... and therefore gained new insight into the teaching of a language" (23:18). Another pre-service teacher felt that her "knowledge was broadened by having to ... research factors about teaching languages" (23:24). One pre-service teacher elaborated, "It made me aware that teaching languages is important and it made me more open-minded about how to teach language and that there are many theorists that talk about teaching languages" (23:28).

8.1.3 The importance of integrating different types of knowledge to better prepare students teachers for the 21st-century classroom

During the analysis, it became clear that the integration of different types of knowledge benefited the students to be better prepared for the 21st-century classroom. When the pre-service teachers were asked whether they felt more equipped for the 21st-century classroom on a scale of 1 (not equipped at all) to 5 (very equipped) after 
completing the assignment, the majority (81\%) of the students felt that they were more prepared. The responses of the pre-service teachers are depicted in Figure 2.

\section{After this assignment, on a scale from 1- 5, do you feel more equipped for the 21st century classroom?}

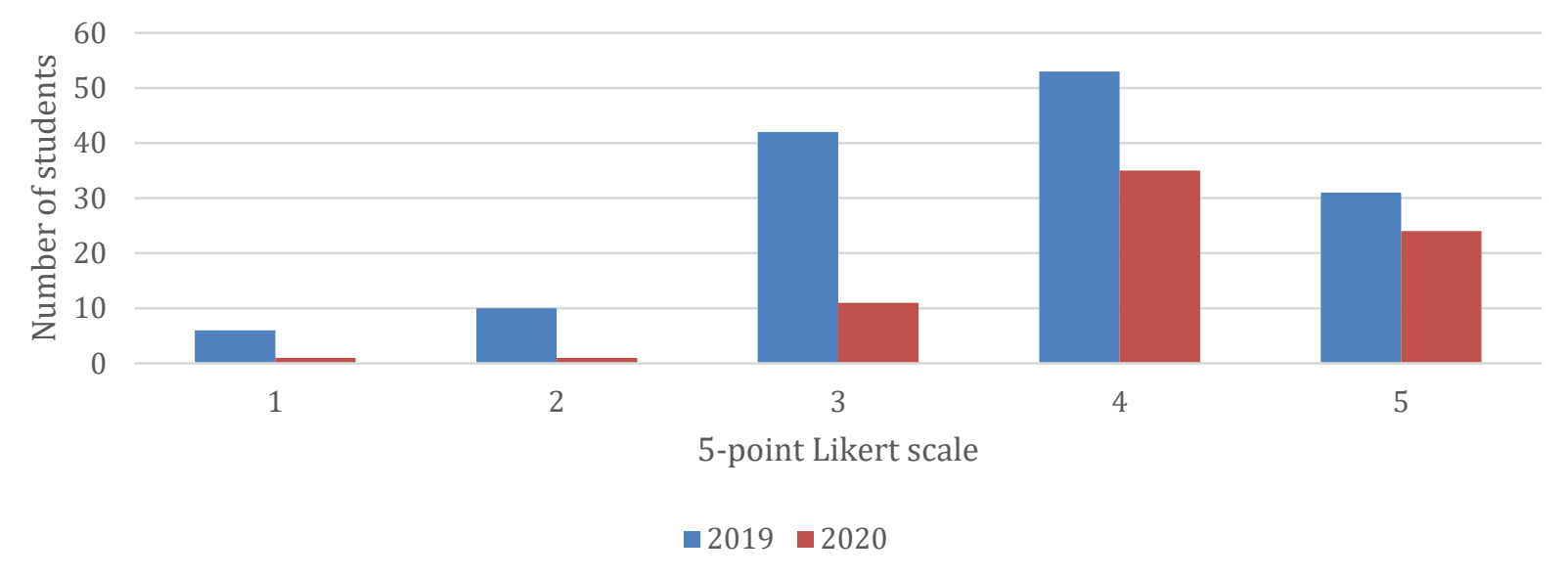

Figure 2: Pre-service teachers' responses to being equipped for the 21st century

The pre-service teachers were also asked, on a scale from 1 (not equipped at all) to 5 (very well equipped), whether they felt more equipped to integrate content, technology and teaching approaches when teaching learners in the Foundation Phase. The data showed that the majority (75.4\%) of the pre-service teachers felt more equipped to integrate different types of knowledge (i.e., TK, CK and PK). This is because the TPACK shows that the mastery of technology skills and confidence in using technology when teaching is the key factor that pre-service teachers should acquire at higher institutions (Flavin, 2017). Furthermore, Lambert and Gong (2010) suggest that preservice teachers need training on how to connect the skills in teaching (PK), content (CK) and technology (TK). When the pre-service teachers were asked why they enjoyed the assignment, they explained that the assignment "prepares us for the future when we are teachers ourselves" (18:4), "prepares us for the technologically advanced classrooms and students" (18:16) and "this type of assignment was the best because it opened us up to more things and what teaching foundation phase or any other phase might be like in the 21st century" (18:17). From the pre-service teachers' responses to this question, it is evident that the integration of different types of knowledge has promoted their ability to teach a language in a technologically advanced classroom.

The pre-service teachers were asked to elaborate on how they would use technology when teaching a language. They listed various technological applications and explained that they would use technology when teaching a language by doing the following: "By playing sound tracks with the correct pronunciation of [sic] the learners to understand better" (24:1), "Google Sites and power-point [sic] to make it more fun" (24:2), playing "educational games" (24:5), "providing educational songs and games" (24:7), finding "resources" (24:7), "using different website for resources and ideas" (24:8) and integrating "songs, videos and blogs when teaching language" (24:13). Some of the pre-service teachers explained that they would create their "own website where children will get easy access to the information they'll need" (24:16) and that "technology can be used to illustrate what is being said by the teacher by the show of pictures that gives meaning" (24:19).

One pre-service teacher explained that this assignment had taught him or her how to "aid my teaching" (24:9). Another pre-service teacher said, "I will use multiple tools with technology as technology is never ending and a lot of resources and tools are available" (24:10). Another pre-service teacher added, "I will use the translate app to help learners if they are not studying in their mother language. Or I will use language games for instance Kahoot, there [sic] will be asked click on the word that is spell [sic] correctly" (24:23). Most of the technological applications the pre-service teachers listed were used when designing their own websites, which shows how the integration of TK, CK and PK within the assignment better prepared them for the 21st century by equipping them with the necessary knowledge of and skills in how to use technology effectively. Wankle (2011) points out that the essence of the TPACK model is the interaction of different types of knowledge needed by a teacher for the 
effective integration of technology when teaching. Another prominent theme that was identified in the data was how the integration of different types of knowledge with the Google Sites assignment promoted authentic learning.

\subsubsection{The use of website design pedagogy promotes authentic learning}

Creating authentic learning activities or experiences for pre-service teachers in the higher education environment continues to be a priority, as it is important for pre-service teachers to understand how to integrate technology to achieve authentic learning (Archambault et al., 2014; Bjekic et al., 2010; Latham and Carr, 2012). The data of this study showed that the use of website design pedagogy promoted authentic learning because, as one pre-service teacher explained, "it is relevant to our everyday life experiences" (18:18). Authentic learning was promoted by having the pre-service teachers experience a sense of ownership, allowing them to express themselves and to research a topic of their choice. The use of Google Sites also stimulated and promoted their critical and creative thinking - aspects associated with authentic learning. Owing to the pre-service teachers having to work in groups, collaborative learning, another characteristic of authentic learning, was evident too.

That the assignment promoted authentic learning was evident in 184 responses where the pre-service teachers explained that they had experienced a sense of ownership when "seeing the end product and knowing that I created that" (17:23), being "able to be proud of the work and being able to say we have created a website" (17:67) and "the whole concept of having a website with your name on it" (17:106). In 37 responses, the preservice teachers used the words "my own", for example "getting to create my own website" $(17: 133,135)$, "designing my own web page" (17:131) and "I was able to apply my own thoughts based on the research I did" (18:20). A sense of ownership was also evident in one pre-service teacher stating "being able to put a touch of myself in something that people will read made it great" (17:28). The use of words such as "my own" and "myself" demonstrates how the assignment promoted ownership, which can be associated with authentic learning.

The assignment also promoted authentic learning by allowing the pre-service teachers to express themselves. There were 53 responses associated with pre-service teachers elaborating on being able to express themselves freely. Some of the pre-service teachers said, for example, that they enjoyed the assignment because "I could raise my voice as a teacher" (17:48), they had "more freedom" (18:1) and it made them feel like they were "some published blogger or researcher" (17:57). One pre-service teacher explained it as follows: "I enjoyed compiling everything about the assignment. Seeing everything come together beautifully was amazing. The introduction about myself made me feel important and knowing that someone out there will read my work" (17:53). One preservice teacher said, "I felt like l expressed myself more constructively. You got to meet me, and put a face to the name when reading my work" (20:9). Another one remarked, "I never knew where to post or how to and this has taught me how to creatively express myself" (22:23).

Another 54 responses demonstrated how the assignment promoted critical and creative thinking, which could also be associated with authentic learning. One pre-service teacher said, "YES YES YES it is a fun way to get hold of your creative side and making something that is yours" (31:4). Another one noted that "this [assignment] gave you a bit more creative freedom" (18:21). Other pre-service teachers wrote that the assignment allowed them "to be creative and it is more about my experiences and not just content-based" (17:21) and "to use my creativity" (17:39). One pre-service teacher stated, "I enjoyed doing something that required me to be creative" (17:132). Another pre-service teacher said, "I prefer this type of assignment because it makes you think creatively and critically" (18:2). According to the pre-service teachers, the assignment "develops critical thinking" (20:10) and "improved my research skills" (22:10), which align with the principles of authentic learning.

Group collaboration as part of this assignment also promoted authentic learning, as the pre-service teachers explained that they had benefited from working in groups. One of the pre-service teachers said, "I really did not know how to do subpages at first; however, with the assistance of my group members I was able to do it" (12:102). Another pre-service teacher elaborated as follows: "I found creating the website very challenging because it was my first time creating a website. At first, I also did not know how to post my work on the website but I got help from my group members who were more knowledgeable than I" (12:150). Other pre-service teachers emphasised that "with the assistance of my group members I was able to do it" (17:62) and "working as a group because we helped each other" (17:74). 
The data make it evident that the design of educational websites using the Google Sites application (i.e., language teaching) adheres to the principles of authentic learning since it develops a sense of ownership and allows for the expression of thoughts and ideas about the teaching of languages and the stimulation of critical and creative thinking. Since the design of websites also requires the application and integration of different types of knowledge, it can be viewed as promoting authentic learning as well and aligns with the principles of the TPACK model. Lastly, creating websites is a complex activity that results in the creation of a tangible product that can be used in real life and focuses on a specific audience (other teachers), which are all characteristics of authentic learning (Herrington, 2006). Since the assignment integrated different types of knowledge that better prepare pre-service teachers for the 21st-century classroom and promote authentic learning, the principles of Vygotsky's ZPD are evident too.

\subsection{The use of website design pedagogy helps pre-service teachers to reach their zone of proximal development}

Various researchers (i.e., Iszatt-White and Kempter, 2013; Moe and Polin, 2016; Vygotsky, 1978) support the opinion that knowledge is co-constructed and that individuals learn from others during group work. Consequently, in this study, pre-service teachers were grouped with their peers to learn from one another and support struggling students. From the data, it was evident that the assignment challenged the pre-service teachers, as $85.7 \%$ of the students explained that they had no prior knowledge of Google Sites or the design of websites. They were then asked to show on a scale of 1 (not at all) to 5 (extremely) how challenging they had found the assignment. Their responses showed that over two years, 172 (80.3\%) of the pre-service teachers had found the assignment challenging. Figure 3 is a depiction of the pre-service teachers' responses.

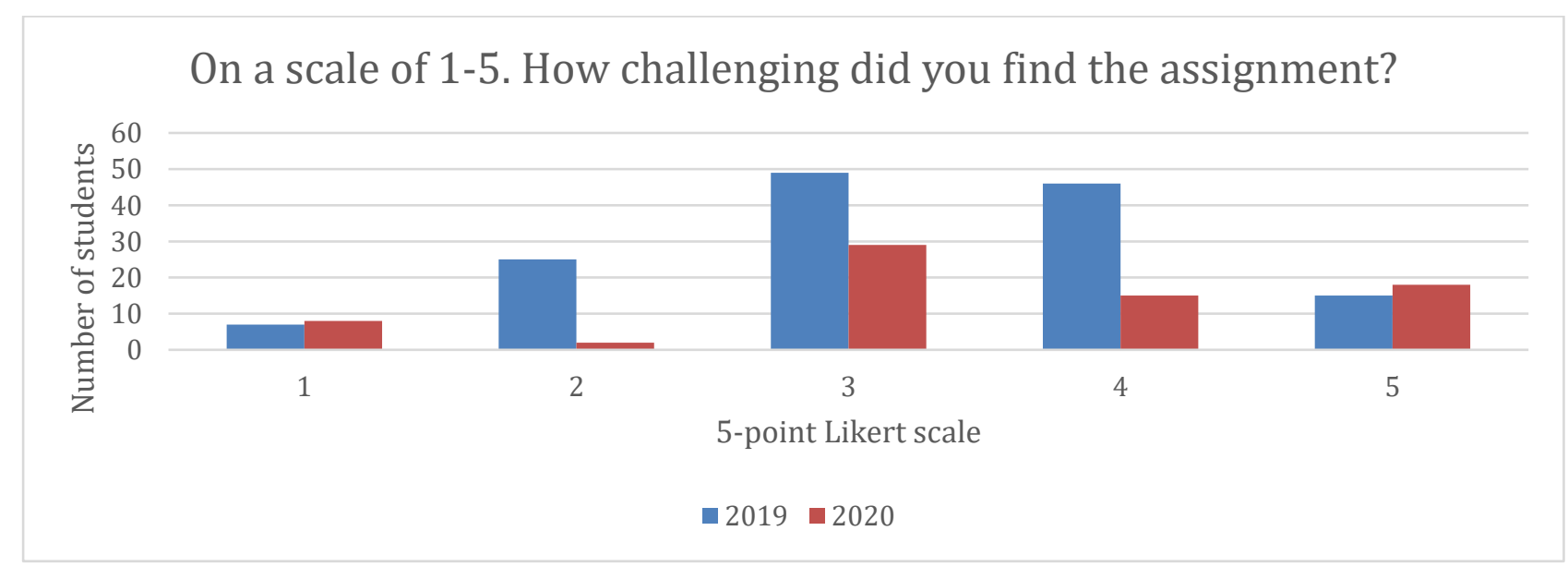

Figure 3: Pre-service teachers' responses to how challenging they had found the assignment

Even though the majority of the pre-service teachers had found the assignment challenging, $84.6 \%$ of the preservice teachers indicated on a scale of 1 (not at all) to 5 (very much) that they had enjoyed creating their own websites as part of the assignment. The figure below depicts the distribution of the pre-service teachers' responses. 


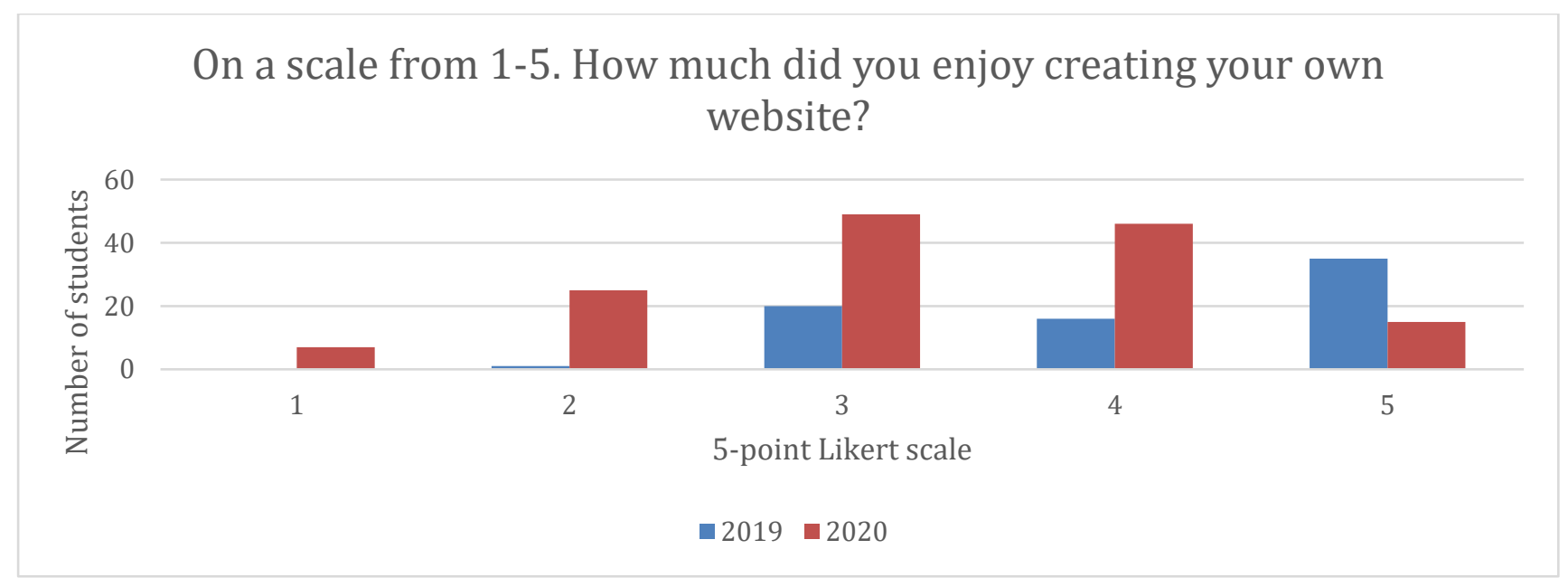

Figure 4: Pre-service teachers' level of enjoyment

The principles of ZPD were evident in responses where the pre-service teachers explained that "the growth and ability to pull through at the end" (17:45) had made the assignment worthwhile and that it "felt good to do something new that I had not been aware I was capable of. It was a [sic] great to see the final product after completion" (17:60). One pre-service teacher said that the assignment "pushes our boundaries" (18:40), which aligns with Vygotsky's ZPD that scaffolding from peers and experienced people assists individuals in performing tasks beyond their level of capabilities. Another pre-service teacher declared, "Everything I did for the assignment was new knowledge" (29:3). Moreover, the assignment was "challenging and rewarding" (19:4) by having the pre-service teachers perform "out of our comfort zones" (19:23).

The ZPD is anchored in the notion that the development of skills and conceptual knowledge is supported by scaffolding from more knowledgeable people, peers or learning tools (Vygotsky, 1978). Scaffolding in this study refers to the training and guidance as well as the instructions and information that the pre-service teachers have received throughout the semester. The pre-service teachers were asked to indicate on a scale of 1 (not at all) to 5 (very well) how they had experienced the training and guidance they had received throughout the assignment. The majority of the pre-service teachers $(88 \%)$ indicated that they found the instructions clear and the guidance sufficient. From their responses, it is evident that the success of an assignment where pre-service teachers are challenged to integrate different types of knowledge and use online platforms, such as Google Sites, with which they are not familiar, requires guidance and clear instructions.

From Figures 2, 3 and 4, it is evident that the findings of this study align with Vygotsky's explanation that the ZPD provides a way of thinking about how individuals develop skills and knowledge through scaffolding, modelling, coaching and authentic learning support to guide the transfer of knowledge and skills to others (cf. Chai, Koh and Tsai, 2010). As the pre-service teachers were challenged by the assignment, but still enjoyed the assignment, gained TK, CK and PK and felt better prepared for the 21st-century classroom, it can be concluded that the assignment had contributed to the pre-service teachers reaching their ZPD.

\section{Conclusion}

In this study, we explored how the design of websites as a pedagogy in higher education could promote quality teaching and learning. Pre-service teachers were tasked, in groups, with designing their own language education websites using Google Sites that consisted of various types of media, such as videos, blogs and images. After completing the assignment, the pre-service teachers provided us with feedback by voluntarily completing an open-ended questionnaire. The main objective of the questionnaire was to investigate the pre-service teachers' experiences and challenges and to identify the possible benefits of designing language education websites.

Based on our findings, we argue that the use of website design technology to design educational websites allows for the integration of different types of knowledge (CK, PK and TK), which aligns with the principles of the TPACK model (cf. Abbitt, 2011). Moreover, integrating different types of knowledge helps to prepare pre-service teachers for the 21st-century classroom, as they are exposed to technology in a meaningful and integrated way. 
Pre-service teachers therefore not only develop technical skills but also knowledge on how to use technology to teach a language, i.e., TPACK.

A key finding of the study was that the use of website design pedagogy promoted quality teaching and learning owing to its adherence to the principles of authentic learning, such as promoting a sense of ownership, allowing students to express themselves and promoting creative and critical thinking as well as collaboration. It was also evident that the use of website design pedagogy helped pre-service teachers to reach their ZPD, as theorised by Vygotsky, as they were challenged to learn and develop new skills with the necessary assistance provided by their lecturers in the form of training workshops, guideline documents and frequent interaction. Overall, we found that the design of language education websites using Google Sites was a successful and effective way to improve the quality of teaching and learning that took place in higher education. The integration of the TPACK model, Vygotsky's ZPD theory and the use of the Google Sites application equipped pre-service teachers with authentic learning that better prepared them to teach in the 21st-century classroom.

\section{References}

Abbitt, J.T., 2011. An investigation of the relationship between self-efficacy beliefs about technology integration and technological pedagogical content knowledge (TPACK) among preservice teachers. Journal of Digital Learning in Teacher Education, 27(4), pp.134-143.

Adams Becker, S., Cummins, M., Davis, A., Freeman, A., Hall Giesinger, C. and Ananthanarayanan, V., 2017. NMC Horizon Report: 2017 Higher Education Edition. Austin, TX: The New Media Consortium.

Allen, I.E. and Seaman, J., 2010. Learning on demand: online education in the United States, 2009. Newburyport, MA: Sloan Consortium.

Alajmi, M., 2013. Faculty members' readiness for e-learning in the colleges of basic education in Kuwait. PhD. University of North Texas.

Archambault, L., DeBruler, K., and Freidhoff, J., 2014. K-12 online and blended teacher licensure: Striking a balance between policy and preparedness. Journal of Technology and Teacher Education, 22(1), pp. 83-106.

Benavot, A., 2015. Literacy in the 21st century: towards a dynamic nexus of social relations. International Review of Education, 61(3), pp.273-294.

Behmanesh, F., Bakouei, F., Nikpour, M., and Parvaneh, M., 2020. Comparing the effects of traditional teaching and flipped classroom methods on Midwifery students' practical learning: the embedded mixed method. Technology, Knowledge and Learning, pp.1-10. DOI: 10.1007/s10758-020-09478-y

Boschman, F., McKenney, S. and Voogt, J., 2015. Exploring teachers' use of TPACK in design talk: the collaborative design of technology-rich early literacy activities. Computers and Education, 82, pp.250-262.

Blinder, A., (2006). Offshoring: the next industrial revolution? Foreign Affairs, 85(2), pp.113-128.

Bjekić, D., Krneta, R., and Milošević, D., 2010. Teacher education from e-learner to e-teacher: Master Curriculum. TOJET Turkish Online Journal of Educational Technology, 9(1), pp. 202-212.

Calvo, N. and Villarreal, Ó., 2018. Analysis of the growth of the e-learning industry through sustainable business model archetypes: a case study. Journal of Cleaner Production, 1(91), pp.26-39.

Chai, C.S., Koh, J.H.L. and Tsai, C.C., 2010. Facilitating preservice teachers' development of technological, pedagogical, and content knowledge (TPACK). Journal of Educational Technology and Society, 13(4), pp.63-73.

Clark, A. and Chalmers, D., 1998. The extended mind. Analysis, 58(1), pp.7-19.

Dolapcioglu, S. and Doğanay, A., 2020. Development of critical thinking in mathematics classes via authentic learning: an action research. International Journal of Mathematical Education in Science and Technology, pp.1-24.

Du Toit, J. and Verhoef, A.H., 2018. Embodied digital technology and transformation in higher education. Transformation in Higher Education, 3(1), pp.1-8.

Ejikeme, A.N. and Okpala, H.N., 2017. Promoting children's learning through technology literacy: challenges to school librarians in the 21st century. Education Information Technology, 22(1), pp.1163-1177.

Fani, T. and Ghaemi, F., 2011. Implications of Vygotsky's zone of proximal development (ZPD) in teacher education: ZPTD and self-scaffolding. Procedia - Social and Behavioral Sciences, 29, pp.1549-1554.

Flavin, M., 2017. Disruptive technology enhanced learning: the use and misuse of digital technologies in higher education. London: Springer.

Gardner, H., 2014. Multiple intelligences: new horizons. Rev. ed. New York, NY: Perseus.

Georgina, D.A. and Olson, M.R., 2008. Integration of technology in higher education: a review of faculty self-perceptions. Internet and Higher Education, 11(1), pp.1-8.

Green, L., Jones, S.A. and Burke, P.A., 2017. School librarians fully online: preparing the twenty-first century professional. Research Journal of the American Association of School Librarian, 20(2017), pp.1-21.

Harvey, D.M. and Caro, R., 2017. Building TPACK in preservice teachers through explicit course design. Technological Trends, 61(1), pp.106-114.

Hassan, B. and Mansor, Y., 2009. Role of academic libraries in promoting information literacy among students of higher learning institutions. Strengthening higher education for a successful workforce. Journal of Learning Design, 8(3), pp.65-77 
Herrington, J., 2006. Authentic e-learning in higher education: design principles for authentic learning environments and tasks. E-Learn: World Conference on E-Learning in Corporate, Government, Healthcare, and Higher Education, 6(1), pp.3164-3173.

Herrington, J., Reeves, T.C. and Oliver, R. (2010) A Guide to Authentic e-Learning. Routledge, New York.

Iszatt-White, M., Kempster, S. and Carroll, B., 2017. An educator's perspective on reflexive pedagogy: Identity undoing and issues of power. Management Learning, 48(5), pp.582-596.

Johnson, L.D., 2012. The effect of design teams on pre-service teachers' technology integration. PhD. Syracuse University.

Kiilu, R. and Muema, E., 2012. An e-learning approach to secondary school education: e-readiness implications in Kenya. Journal of Education and Practice, 3(16), pp.142-148.

Kirkwood, A. and Price, L., 2014. Technology-enhanced learning and teaching in higher education: what is 'enhanced' and how do we know? A critical literature review. Learning, Media and Technology, 39(1), pp.6-36.

Koehler, M.J. and Mishra, P., 2009. What is technological pedagogical content knowledge? Contemporary Issues in Technology and Teacher Education, 9(1), pp.60-70.

Koehler, M.J., Mishra, P., Kereluik, K., Shin, T.S. and Graham, C.R., 2014. The technological pedagogical content knowledge framework. In: N.J., Bishop, E., Boling, J., Elen, V., Svihla, eds. Handbook of research on educational communications and technology. New York, NY: Springer. pp.101-111.

Lambert, J. and Gong, Y., 2010. 21st century paradigms for pre-service teacher technology preparation. Computers in the Schools, 27(1), pp.54-70.

Latham, G. and Carr, N., 2015. Building on authentic learning for pre-service teachers in a technology-rich environment. Journal of Learning Design, 8(3), pp.65-77.

Lombardi, M.M., 2007. Authentic learning for the 21st century: an overview. Educause Learning Initiative, 1, pp.1-12.

Lye, L.T., 2013. Opportunities and challenges faced by private higher education institutions using the TPACK model in Malaysia. Procedia - Social and Behavioral Sciences, 91, pp.294-305.

Mishra, P. and Koehler, M.J., 2006. Technological pedagogical content knowledge: a framework for integrating technology in teacher knowledge. Teachers College Record, 108(6), pp.1017-1054.

Nwana, S., 2008. Challenges in the application of e-learning by secondary school teachers in Anambra state. Lagos: Okari Publishers.

Moe, R. and Polin, L., 2016. TPACK as mediated practice. In: S. Bryans-Bongey and K.J. Graziano, eds. Online teaching in K12: models, methods, and best practices for teachers and administrators. New Jersey, NJ: Information Today. pp.7390.

Saubern, R., Urbach, D., Koehler, M. and Phillips, M., 2019. A Rasch analysis of TPACK proficiency: describing what it means to have more or less TPACK. Research Highlights in Technology and Teacher Education, p.13.

Shulman, L., 1987. Knowledge and teaching: foundations of the new reform. Harvard Educational Review, 57(1), pp.1-23.

Skhephe, M., Caga, N.P. and Boadzo, R.M.K., 2020. Accounting teachers' readiness for e-learning in the Fourth Industrial Revolution: a case of high schools in the Eastern Cape, South Africa. Perspectives in Education, 38(1), pp.43-57.

Tai, S.-J.D., 2015. From TPACK-in-action workshops to classrooms: CALL competency developed and integrated. Language Learning and Technology, 19(1), pp.139-164.

Thammasaeng, P., Pupat, P. and Phetchaboon, S., 2016. Needs assessment of information and communication technology literacy (ICT Literacy) of students in secondary educational service area. International Journal of Emerging Technologies in Learning, 11(12), pp.9-13.

United States Department of Education, 1996. Getting America's students ready for the 21st century: meeting the technology literacy challenge. A report to the nation on technology and Education. Washington, DC: Department of Education.

Vygotsky, L.S., 1978. Interactions between learning and development. In: M. Cole, V. John-Steiner, S. Scribner and E. Souberman, eds. Mind in society, the development on higher psychological processes. London: Harvard University Press, pp.79-91.

Waghid, Z. and Waghid, F., 2016. Examining digital technology for (higher) education through action research and critical discourse analysis. South African Journal of Higher Education, 30(1), pp.265-284.

Wainer, J., Dwyer, T., Dutra, R.S., CoMerleau-Ponty, A., Magalhães, V.B., Ferreira, L.R., Pimenta, V.A. and Claudio, K., 2008. Too much computer and Internet use is bad for your grades, especially if you are young and poor: results from the 2001 Brazilian SAEB. Computers and Education, 51(1), pp.1417-1429.

Wankle, C., 2011. Teaching arts and science with new social media: volume 3. New York, NY: Emerald Group Publishing. 